\title{
2
}

\section{A BRIEF HISTORY OF DEFINING SEX AND GENDER}

For the purposes of this book, our understanding of "sex" and "gender" in the United States can be described as having moved through three stages over the past seven decades. ${ }^{3}$ The first stage was dominated by a simple biological understanding of sex. Prior to the advent of psychologists investigating what we would now call gender dysphoria in the 1960s and feminist theory and research in the 1970s, the terms "sex" and "gender" were rarely in dialogue, and "gender" was scarcely used at all in English.

The online Merriam-Webster Dictionary's first definition of the noun "sex" is "either of the two major forms of individuals that occur in many species and that are distinguished respectively as female or male especially on the basis of their reproductive organs and structures." Prior to the past 50 years, the word "gender" was used in English primarily to refer to grammatical gender as found in various languages, such as Spanish, French, and German. "Gender" finds common etymological roots with words such as genre and genus, related to classification (Connell \& Pearse 2015,9). The most common gender divisions include masculine, feminine, and neuter. In most cases the gender assignment is arbitrary, and in fact a word such as "manliness" has feminine grammatical gender in some languages (Spanish hombría, masculinidad, German Männlichkeit, Polish męskość, among others).

Computer-assisted research by linguistics professor Stefan Th. Gries with law professors Brian Slocum and Lawrence Solan found that aside from references to grammatical gender, "in American English in the 1960s, gender was an extremely uncommon word" (Brief for Amici Curiae 2019, 23). Though the word "gender" certainly could be used correctly to refer to males and females, masculinity and femininity, it was relatively rare to do so prior to the 1970s.

Thus, the first stage can be described as treating the categories of "woman" and "man," "male" and female," as biological givens. Stereotypically, behaviors and 
traits thought of as "manly" or masculine would be assumed to be appropriate for men, and "womanly" or feminine for women. Such assumptions are described as the biological determinist or biological essentialist understanding of sex and gender, and it has been the dominant viewpoint toward the sexes for much of U.S. history, as subsequent chapters illustrate. Sociologists call this the "natural attitude" toward sex and gender (Garfinkel 1967; Kessler \& McKenna 1978); that is, the taken-for-granted belief that people can be classified biologically into one of only two "natural" categories, each of which is determined by the presence of particular genitals, and for which exceptions are temporary or pathological - that is, a sign of physical abnormality.

The second stage of defining "sex" and "gender" emerged from work in two areas-psychiatry and feminist scholarship. A thorough historical account of this period is beyond the scope of this book, ${ }^{4}$ but a few key moments deserve discussion.

The distinction between the words "sex" and "gender" in English first emerged in the 1950s and 1960s in the specialized literature of "psychiatrists and other medical personnel working with intersexed and transsexual patients" (Moi 1999, 21; see also Mikkola 2019). Psychiatrists and psychologists needed to describe and explain the phenomenon of a patient who felt trapped in the proverbial "wrong body," thus it became useful to distinguish a person's biological sex from their psychological orientation. In a 1955 publication, New Zealand psychologist John Money and his colleagues introduced the notion of "gender role" based on their study of "hermaphrodites" 5 to distinguish attitudes and behaviors that were conceptually distinct from biological sex characteristics. According to Money, "Gender role is appraised in relation to the following: general mannerisms, deportment and demeanor; play preferences and recreational interests; spontaneous topics of talk in unprompted conversation and casual comment; content of dreams, daydreams and fantasies; replies to oblique inquiries and projective tests; evidence of erotic practices, and, finally, the person's own replies to direct inquiry" $(1955,302) .{ }^{6}$ And in a 1963 paper presented to the International Psycho-Analytic Congress, American psychoanalyst Robert Stoller introduced the concept of "gender identity" to describe "the sense of knowing to which sex one belongs, that is, the awareness 'I am a male' or 'I am a female"" $(1964,220) .^{7}$

The 1980 edition of the American Psychiatric Association's Diagnostic and Statistical Manual of Mental Disorders (DSM-III) described the condition of a conflict between one's biological sex and one's gender identity as "gender identity disorder," but the latest edition (DSM-V 2013) refers to it as "gender dysphoria." While psychiatrists debate whether such feelings should be considered a "disorder," the point here is that efforts by Stoller and other psychologists led to treating "gender" as a psychological rather than a biological concept.

The belief that men and women have essentially different natures, rooted in biology, has dominated thinking about sex roles throughout much of human history. Thus, drawing a distinction between biological sex and psychological 
gender was an important step for feminists challenging the legacy of biological essentialism that has been used to justify discrimination against women (Bem 1993; Fausto-Sterling 1985). In a number of influential feminist texts in the second half of the 20th century, "sex" was defined as a biological category, whereas "gender" came to be understood as a culturally dependent social or psychological category. The classic formulation is found as early as 1972 in sociologist Ann Oakley's book, Sex, Gender, and Society: "'Sex' is a word that refers to the biological differences between male and female: the visible difference in genitalia, the related difference in procreative function. 'Gender' however is a matter of culture: it refers to the social classification into 'masculine' and 'feminine"," (1972, 16).

Sandra Lipsitz Bem's work as a psychologist is a useful illustration of the intellectual trend of treating sex and gender as distinct, especially because her work was influential in and beyond her home discipline of psychology.

Bem's feminism originated in the 1960s ("Early Career Awards" 1977). In 1970 she and her husband Daryl J. Bem published "Case Study of a Nonconscious Ideology: Training the Woman to Know Her Place” (Bem \& Bem 1970). The paper argued that girls are not encouraged to consider professional careers as they grow up and women face discrimination in the workplace. A revision of the paper was published the next year for the Pennsylvania Department of Public Instruction for distribution to all Pennsylvania high school guidance counselors. In 1973, Sandra and Daryl Bem coauthored research (originally conducted as part of legal testimony in sex discrimination cases) of how "sex-biased" job advertising leads to discrimination (Bem \& Bem 1973).

In 1974, Bem introduced her Sex-Role Inventory in "The Measurement of Psychological Androgyny." The inventory built on earlier work by psychologists to assess masculinity and femininity as personality traits for diagnostic purposes, ${ }^{8}$ but was distinctive because it "treats masculinity and femininity as two independent dimensions, thereby making it possible to characterize a person as masculine, feminine, or 'androgynous'" $(1974,155)$. The traits represented the dominant thinking about what counts as masculine and feminine at the time, based on subjects' perceptions of what attributes are desirable and appropriate for a man or a woman. The Bem Sex-Role Inventory, or BSRI, went on to become one of the more influential psychological measurement instruments of the past 50 years.

Bem's project and others like it were important because they signaled a break from the long legacy of biological essentialism. Challenging the belief that one's biological sex determines one's psychological make-up, Bem argued that the traits we normally associate with masculinity and femininity could be found in males and females alike, and that a given person might score high on the masculinity scale, or on the femininity scale, or both. These traits, Bem suggested, were a matter of socialization. The "sex-typed person" is "someone who has internalized society's sex-typed standards of desirable behavior for men and women" (155). 
The BSRI contains 60 items, categorized as follows:

Feminine Items

$\begin{array}{lll}\text { Affectionate } & \text { Sympathetic } & \text { Sensitive to the needs of others } \\ \text { Understanding } & \text { Compassionate } & \text { Eager to soothe hurt feelings } \\ \text { Warm } & \text { Tender } & \text { Loves children } \\ \text { Gentle } & \text { Yielding } & \text { Cheerful } \\ \text { Shy } & \text { Flatterable } & \text { Loyal } \\ \text { Soft-spoken } & \text { Gullible } & \text { Does not use harsh language } \\ \text { Childlike } & \text { Feminine } & \end{array}$

\section{Masculine Items}

$\begin{array}{lll}\text { Defends own beliefs } & \text { Independent } & \text { Assertive } \\ \text { Strong personality } & \text { Forceful } & \text { Has leadership abilities } \\ \text { Willing to take risks } & \text { Dominant } & \text { Willing to take a stand } \\ \text { Aggressive } & \text { Self-reliant } & \text { Athletic } \\ \text { Analytical } & \text { Self-sufficient } & \text { Makes decisions easily } \\ \text { Individualistic } & \text { Masculine } & \text { Competitive } \\ \text { Ambitious } & \text { Act as a leader } & \end{array}$

\section{Neutral Items}

$\begin{array}{lll}\text { Adaptable } & \text { Conceited } & \text { Conscientious } \\ \text { Conventional } & \text { Friendly } & \text { Happy } \\ \text { Helpful } & \text { Inefficient } & \text { Jealous } \\ \text { Likable } & \text { Moody } & \text { Reliable } \\ \text { Secretive } & \text { Sincere } & \text { Solemn } \\ \text { Tactful } & \text { Theatrical } & \text { Truthful } \\ \text { Unpredictable } & \text { Unsystematic } & \end{array}$

These items can be thought of as a catalogue of socially approved sex-specific traits for men and women in 1974. Interestingly enough, Bem did not use the word "gender" in the article. A few years later, however, Bem made another important contribution with the publication of "Gender Schema Theory: A Cognitive Account of Sex Typing" (1981). Bem defines "schema" as "a cognitive structure, a network of associations that organizes and guides an individual's perception" (355). Bem contends that the "sex typing" socialization process is how "a society transmutes male and female into masculine and feminine" (354). Gender schema "becomes a prescriptive standard or guide" that "prompts the individual to regulate his or her behavior so that it conforms to the culture's definitions of maleness and femaleness" (355). Offering empirical studies in support of her argument, Bem suggests that society "teaches" children a "substantive network of sex-related 
associations" that become cognitive schema through which the world is understood, and that "the dichotomy between male and female has extensive and intensive relevance to virtually every aspect of life" (362). Indeed, later research by social scientists found that by age five children already have developed clearly defined notions of what constitutes appropriate behavior for men and women (Lytton \& Romney 1991), and it should be no surprise that media portrayal of gender roles plays a significant gender socializing function (Ward \& Grower 2020).

Bem followed up the introduction of her theory with efforts to encourage parents to raise what she described as "gender-aschematic children"-also described at the time as "nonsexist" or "gender-liberated" child rearing (1983). Bem's goal was no less than to reduce the relevance of "gender" as a concept altogether: "[H]uman behaviors and personality attributes should no longer be linked to gender, and society should stop projecting gender into situations irrelevant to genitalia" $(1983,616){ }^{9}$

Bem was one of many feminists arguing that it is societal pressure, not biology, that shapes women's and men's understanding of gender roles. What is particularly noteworthy for our purposes is the fact that she attempted to specify the attributes defining masculine and feminine and to provide a simple paper and pencil test to operationalize and, in a sense, measure gender.

Various scholars documented the sort of normative messages that girls receive during socialization, such as "defer to men," "nurture others," and "be nice," among others (see, for example, Unger 1975; Gilbert \& Scher 1999). The sources of, and harm done by, gender typing and stereotypes became important topics especially to feminist psychologists (see, for example, Eagly \& Steffen 1984). The Bem Sex Role Inventory became the most widely shared measure of gender, particularly for femininity (Mahalik et al. 2005, 418).

Efforts to identify the beliefs and attitudes associated with masculinity followed, including the Macho Scale (Villemez \& Touhey 1977), a measure primarily of antifemininity and patriarchal beliefs; the Attitudes Toward Masculinity Transcendence Scale (Moreland \& Van Tuinen 1978); and the Brannon Masculinity Scale (Brannon \& Juni 1984) —an influential measure of masculinity ideology.

Such work illustrates the important intellectual trend of the 1970s and 1980s to separate the concepts of sex and gender. One indication of the growing awareness and importance of the idea of "gender" is that the use of the word grew significantly in publications from 1970 onward..$^{10}$ The word gender "was rapidly popularized in feminist political discourse as a tool to intervene in arguments against biology" (Fausto-Sterling 2016, 197). It did not take long for it to become standard in college textbooks in the humanities and social sciences to distinguish between sex as biological and gender as cultural/psychological.

For example, the glossary of a popular introductory textbook in sociology in 1981 noted: "Sex (male and female): Refers to the division of the human species into the biological categories of male and female" and "Gender: Refers to social conceptions about what personality trait and behavior are appropriate for members of each sex" (Robertson 1981, 629, 633). A textbook in psychology noted that "Femininity and masculinity are socially defined terms that are added to the 
biologically determined sex class of the individual. Gender defines the social and cultural meanings brought to each anatomical sex class; that is, children learn how to 'pass as' and 'act as' members of their assigned sexual categories" (Lindesmith, Strauss, \& Denzin 1999, 16).

Many authors and institutions continue to describe the difference between sex and gender as one of biology versus socialization. For example, in an essay on gender and sport, one finds "sex 'refers to a person's biological status' and can be identified by 'sex chromosomes, gonads, internal reproductive organs, and external genitalia' while gender refers to 'the attitudes, feelings, and behaviors that a given culture associates with a person's biological sex'” (Fisher, Knust, \& Johnson 2013, 21, quoting the American Psychological Association 2011).

In a 2018 article titled, "Sex and Gender: What is the Difference?" science writer Tim Newman wrote in Medical News Today: "In general terms, 'sex' refers to the biological differences between males and females, such as the genitalia and genetic differences. 'Gender' is more difficult to define, but it can refer to the role of a male or female in society, known as a gender role, or an individual's concept of themselves, or gender identity." Also in 2018, researchers with the World Health Organization noted that, "Gender refers to the roles, behaviours, activities, attributes and opportunities that any society considers appropriate for girls and boys, and women and men. Gender interacts with, but is different from, the binary categories of biological sex" (Manandhar et al. 2018).

The case for what has been described as the social construction of gender was strengthened by a burgeoning scholarly literature documenting the cultural variability of gender roles, both over time and across cultures. Such scholarship, too voluminous to summarize thoroughly here, includes historical and cross-cultural research that documents the fact that what is considered "normal" and "appropriate" for men and women is far from universal. For example, sociologist Raewyn Connell's influential book, Masculinities (1995, 2005), became a classic on the cultural specificity of gender role socialization that documents the notion of specific dominant or "hegemonic" understandings of masculinity.

Sometimes such historical or cultural gender variability seems trivial, such as the fact that knitting was once associated with men, especially sailors and fishermen, prior to the Victorian age; or the fact that over the past century, the genderappropriate color for boys or girls-blue or pink-has varied (Paoletti 2012; Del Giudice 2017). In other cases, the variability is quite consequential, such as the appropriateness or even legality of women holding a paying job, driving a car, or even being seen in public.

Anthropological and sociological scholarship on what has become known as third gender or third sex further illustrates the cultural variability of sex/gender. Gilbert H. Herdt's collection, Third Sex, Third Gender: Beyond Sexual Dimorphism in Culture and History (1994) was an important landmark in such scholarship. How "third genders" are understood varies, of course, from culture to culture, but several examples can illustrate their significance. Māh $\bar{u}$ translates to "in the middle" in Kanaka Maoli (Hawaiian) and Maohi (Tahitian) culture. The term is used to 
describe those fitting into an indeterminate, intermediate gender that has both feminine and masculine qualities who play important cultural roles, and the māhu phenomenon "defies reduction to any of the notions of gender familiar to us in the West" (Robertson 1989, 314). As a recent article on CNN reports, "Their gender identity has been accepted on the island [Tahiti] since time immemorial, and mahu traditionally play key social and spiritual roles, as guardians of cultural rituals and dances, or providers of care for children and elders" (Ponsford 2020). In the early 21 st century, the term mahuwahine was coined to refer specifically to what we would consider a male to female transgender identity (Ellingson \& Odo 2008).

In recent decades the term "Two Spirit" has been used to describe someone who fulfills nontraditional gender roles in Native American cultures and that Europeans actively discouraged (Brayboy 2018; Roscoe 1998). The label Two Spirit also has been criticized as eliding differences across groups. For example, for the Diné (Navaho) people of the southwestern United States, Nádleehi refers to a social category that we would describe as gender variable. Their role in the community is a fluid one, as Nádleehí may express their gender differently on different days, different situations or contexts, and when holding positions that are traditionally filled by men or women. In Diné culture, the role of Nádleehí is recognized, accepted, and honored by members of the community and is a status unique to the Diné people (Epple 1998; Roscoe 1998).

Although the traditional cultural term does not align perfectly with Western definitions, fa'afafine are people who identify as being nonbinary or having a third gender in Samoa, American Samoa, and the Samoan diaspora. Fa'afafine are considered male at birth, but have a strong affinity toward feminine activities and a feminine identity, and take part in daily work training given to women. The term translates as "in the manner of a woman." Fa'afafine have been part of Samoan culture for centuries, long before Western notions of "transgender" emerged (Dolgoy 2000).

There are a number of other examples throughout the world of what we would now describe as gender variance. Though it is possible to describe such gender nonconformists using contemporary language, such as transgender or nonbinary, doing so misses the cultural specificity of the phenomenon. Indeed, some scholars have suggested certain cultures have a fourth or even a fifth gender (Graham 2007; Trumbach 1994). The point is simply that since the emergence of scholarship in the 1970s and 1980s that treats gender as a matter not of biology but of socialization, examples across history and cultures continue to accumulate, often pointing to centuries-old traditions and practices. ${ }^{11}$

$$
* * *
$$

The second stage I have described has much to commend itself and it remains enormously influential. In many contexts, it has proven to be a useful framework to think about sex and gender. We are now in a third stage in which authors, in different ways and in different situations, sometime seek to collapse the categories of sex and gender. Because the motivations and purposes of those seeking to 
reconsider definitions of sex and gender are quite varied, a simple "this happened and then that happened" narrative would be misleading. Accordingly, I hope a more thematic approach can illustrate the complexity of the current definitional landscape. Specifically, I identify three strands of thinking that have emerged and proven influential.

The first strand of thought I want to identify can be described as the scientific argument for challenging the traditional sex categories of male and female. If one defines "sex" as biological and "gender" as psychological or cultural, then who has the right and the relevant expertise to define those terms? Because "gender" was introduced into the scholarly literature from the perspective of social scientists and humanists, and in light of the compelling evidence for the cultural and historical variability of gender norms that exists, it was not difficult for the idea that "gender is socially constructed" to become widely accepted. But what about "sex," understood as a biological category and hence the purview of natural science? This first strand accepts the epistemological authority of science; that is, the belief that scientific definitions are somehow more "real" or certain than other kinds of knowledge. Specifically: The scientific argument is that a nontrivial number of humans defy the traditional biological ways of defining male and female.

We typically view the number and type of sex-related genes and chromosomes as determining our sex ( $X X$ for women, $X Y$ for men), and we assume our genes determine external genitalia, internal reproductive anatomy (such as the uterus in females), sex hormone levels produced by the body (such as testosterone level), and the type of gonads (ovaries or testicles). But the situation is more complicated than that. ${ }^{12}$ The $S R Y$ (sex determining region $\mathrm{Y}$ ) gene is found on the $Y$ chromosome. The protein produced by this gene initiates processes that cause a fetus to grow male gonads and stop the development of female reproductive body parts (uterus and fallopian tubes). However, it is possible for a SRY gene to end up on an $X$ chromosome and thus for someone with XX chromosomes to grow male characteristics including testes. This is called the " $46, X X$ testicular disorder" and occurs in $0.005 \%$ of births ( 1 in 20,000). Alternatively, it is possible for a person with $X Y$ chromosomes to develop typical female external genitalia, a condition known as the Swyer Syndrome, which is estimated to occur in 1 in 80,000 births. Furthermore, as many as $0.005 \%$ of $X Y$ males (2 to 5 per 100,000) experience androgen insensitivity, where their bodies do not respond to certain male sex hormones, known as androgens, and have mostly female external sex characteristics or "signs of both males and female sexual development" (U.S. National Library of Medicine 2020). Other sorts of genetic variations are possible as well. In short, even if we define male and female strictly according to the science of genetics, not every human neatly falls into one or the other category.

Societies have long recognized the fact that some people are born, for example, with both male and female genitalia, and for centuries such individuals would be described as hermaphrodites. Today, a person whose body varies from the statistical norm for males and females in one or more of the areas described here may be categorized as "intersex" or having "Differences in Sex Development" (DSD). 
Just how many DSD people there are in the world is not known with precision. Because there is no systematic record kept of DSD births, some of the physical traits covered by broader definitions may not be discovered until puberty, attempts are made to conceive a child, or through genetic tests. Nonetheless, scientists have generated estimates based on the available data. Not surprisingly, how many DSD individuals there are depends on how one defines "intersex" or DSD. Using a narrow definition limited to cases where chromosomal sex is inconsistent with phenotypic sex (observable body parts), or in which the phenotype is not classifiable simply as either male or female, one estimate is as low as 0.018\% (Sax 2002). Using a broader definition of any deviation from the prototypical male/female categories at the chromosomal, genital, gonadal, or hormonal level, biologist Anne FaustoSterling estimates the figure could be as high as $1.7 \%(2000) .{ }^{13}$ More recently, estimates of the number of people described as having DSD have a similarly broad range. Medical conditions "in which an individual's anatomical sex seems to be at odds with their chromosomal or gonadal sex" are quite rare-one in 4,500 or $0.02 \%$ (Ainsworth 2018), a figure similar to Sax's estimate. Some scientists feel that definition is too narrow. Eric Vilain, a clinician and former director of the Center for Gender-Based Biology at the University of California, Los Angeles, for example, points out that the "most inclusive definitions point to the figure of 1 in 100 people having some form of DSD" (Ainsworth 2018).

Fausto-Sterling has suggested, more as a thought experiment than as a serious policy proposal, that we imagine humans as divided into five sexes. Suggesting that the category of "intersex" was too broad, she suggested three subcategories be recognized: "the so-called true hermaphrodites, whom I call herms, who possess one testis and one ovary (the sperm- and egg-producing vessels, or gonads); the male pseudohermaphrodites (the 'merms'), who have testes and some aspects of the female genitalia but no ovaries; and the female pseudohermaphrodites (the 'ferms'), who have ovaries and some aspects of the male genitalia but lack testes" $(1993,21)$.

Fausto-Sterling criticized the Trump administration's Department of Health and Human Services efforts to define sex solely as male or female "based on immutable biological traits identifiable by or before birth" as based on "biological error" (2018). Noting that sexual development is "multilayered" and that the layers (such as chromosomal and hormonal) may be in conflict or resist simple binary division, she argued that the policy advocated by the Department of Health and Human Services "flies in the face of scientific consensus about sex and gender" (2018). Fausto-Sterling's work will be discussed again in this book, but for now the point is that she represents a biologist (whose Ph.D. is in Developmental Genetics) who is often cited as providing scientific reasons to challenge the dominance of the twosex system (Fausto-Sterling 2020a, 2020b).

The second strand, by contrast, does not defer to the authority of scientific definitions but instead stresses that scientific definitions are social constructions, devised by scientists to meet certain needs and interests and subject to change. Thus, like gender, "sex" is also a socially negotiable category. 
The claim that scientific definitions are more stable than nonscientific definitions typically depends on the idea that the referents of scientific analysis are objective and represent what are called "natural kinds." As philosopher Jerry Fodor summarizes the claim, "Science discovers essences, and doing science thereby links us to natural kinds as such" $(1998,158)$. The natural sciences, including biology, are assumed to be relatively immune to the challenges of redefinition. As historian and philosopher of science Thomas S. Kuhn puts it, "Their truths (and falsities) are thought to transcend the ravages of temporal, cultural, and linguistic change" (1989, 23).

The vocabulary of science provides what philosopher Saul Kripke called "rigid designators" that correspond to natural, not socially constructed, kinds. Kripke provides the example of gold - " $[\mathrm{P}]$ resent scientific theory is such that it is part of the nature of gold as we have it to be an element with atomic number 79" (1980, 125). Thus, "gold" is a "rigid designator, whose reference is fixed by its "definition"” (1980, 136). In this line of thinking, "male" and "female" are rigid designators that refer to natural (biological) not social categories, and it is consistent with normal scientific progress if a third category, such as "DSD," is added.

The history of science, however, challenges the idea that science produces permanently "rigid" designators. As Kuhn (1970) and other historians have demonstrated, scientific definitions are always understood in the context of a particular scientific theory, designed to meet specific needs and interests. Theories change. Kuhn notes that the concept of an atomic number, used to identify gold, relies on a particular atomic-molecular theory, and only while such a theory "endures do the names it categorizes designate rigidly" (1990, 315).

A well-known example from history is the case of phlogiston, which was once considered a physical substance that is contained within certain objects and released during combustion. It was as real and empirically verifiable and measurable as any other scientific concept of its time. Now, of course, the theory of phlogiston has been superseded by a theory of gases in which phlogiston is no longer considered real (White 1973). The term has changed its status from a hypothesized rigid designator to fiction.

Not all examples of conceptual evolution are as dramatic as the rise and fall of phlogiston, of course. But most philosophers of science today agree that all scientific terms are similarly dependent on a larger set of beliefs, or theory. Even elementary concepts such as "force," "species," "heat," "element," and "temperature" have evolved over time as scientists revise their theories (Kuhn 1990, 313). ${ }^{14}$ The controversy over whether to classify Pluto as a planet is the result of changing definitions promulgated by the International Astronomical Union. Once the IAU changed its definition of planets, it decided that Pluto did not meet all three of its definitional criteria and hence no longer counted as a planet. Even scientific definitions, then, may be described using the grammar of a regulatory definition: " $\mathrm{X}$ counts as $\mathrm{Y}$ in context C" if we think of a specific scientific theory as functioning as a historically situated context: "Gold counts as atomic number 79 in atomic/ molecular theory," or "Pluto does not count as a planet according to IAU's criteria." 
The point of this second strand, then, is to apply the lesson of the history of science to our understanding of the biological categories of the sexes. Scientific language evolves to meets the needs and interests of specific scientific communities, and the current ways of categorizing humans' biological sex is no less of a historically situated social construction than other scientific definitions. This is not to say that biological entities are not real, which is a common misinterpretation of describing a belief or practice as socially constructed. Rather, it is to call attention to the fact that emphasizing different definitional attributes (hormones versus chromosomes, for example) for defining and categorizing woman and men, females and males, involves a choice of what values, interests, and purposes we see our definitions advancing. Developmental biologist Rebecca R. Helm, for example, posted a widely circulated series of tweets in December 2019 stressing how complicated the idea of biological sex can become (Helm 2019). She notes, for example, that a person can be born with XY chromosomes but if the SRY gene appears on the X chromosome instead of the $\mathrm{Y}$, that person could be physically female, chromosomally male, and genetically female. So which attribute should be considered definitive? In personal correspondence, Helm noted that, "as a developmental biologist, I define male/female as organisms producing sperm/eggs" (2020, emphasis added; see also Griffiths 2020). For the purposes of research as a developmental biologist, production of sperm or eggs (gametes) is "the key feature of biological sex." However, Helm is quick to note that, in other contexts, using gametes as the definitive attribute for biological sex for categorizing humans "would be extremely problematic" (2020).

Similarly, historian and philosopher of science Sarah S. Richardson argues against binary essentialist conceptions of sex and advocates what she describes as "sex contextualism" for the study of sex-related biological variables in basic, preclinical biomedical research. She argues that there are multiple ways to define or "pragmatically operationalize" sex in biomedical research, especially in a laboratory context where the focus might be on hormone levels or chromosomes, for example, or involve "laboratory-tailored materials and technologies" (2021). Inferences about humans may be based on other species with quite different sex-related processes, such as roundworms known as Caenorhabditis elegans. Difference in hormone levels at different ages of mice indicates the most useful interpretation of the data would posit four sex categories, not just two. In short, Richardson's analysis of a series of laboratory studies concludes that the definition/operationalization depends on the specific research context and purpose, so sex should be understood contextually (2021).

In short, as we will see in Part II of this book, the question of whether person $\mathrm{X}$ is male or female may have more than one correct answer. Those that want to rely on the authority of science to end the debate on how to define sex will be disappointed, as more than one definition is defensible, and the applicability of such definitions to public policy matters is open to debate.

The first two strands I have identified focus on destabilizing the concept of biological sex-the first strand by accepting the epistemological privilege of scientific 
knowledge but pointing out how the category of DSD people challenges the exclusivity of the categories of male and female, and the second strand by emphasizing that scientific categories are always dependent on theories that are open to revision, and hence can be thought of as revisable social constructions. The point of both strands is that treating sex as a biological "given" that transcends social and cultural differences is not as obvious as once thought, and hence separating sex and gender relying on the assumption that gender is socially constructed while sex is not is no longer a safe assumption to make.

A third strand suggests that even if one could point to clear biological differences between the sexes, the meaning and significance of those differences is a product of social and cultural factors. That is, the concept of gender would not have emerged if there had not already been considerable cultural baggage associated with ideas of what it means to be male or female, even if those beliefs were not yet categorized as "gender" beliefs. As Judith Butler argues, cultural beliefs about what we now call gender figure in "the very apparatus of production whereby sexes themselves are established" $(1999,11)$. That is, a culture's ideas about gender shape how we understand biological sexes $(1999,139)$.

As an example, think about the contemporary practice of "gender reveal" parties. Friends of a couple expecting a baby gather and a dramatic "reveal" occurs that is always coded male or female, typically with blue or pink objects. The "meaning" of an ultrasound reading is that it signifies a gender-typically, if a penis and scrotum are observed, the prenatal assignment is a boy; otherwise, it is a girl. Even before the baby is born, a host of cultural beliefs and practices are thus activated that reinforce the dominant cultural gender norms. Obviously, the relevant body parts of a baby are "real," but according to Butler, social conditioning makes those body parts meaningful (and gendered). Once declared a boy or girl, the actions of parents, friends, institutions such as churches, schools, the medical establishment, and popular culture all work to socialize the child as to what it means to be a boy or girl. "Society" - if I may use the term as shorthand for the wide variety of socializing agents - both conveys messages about what it means to be a boy or girl, and serves as audience for girls' and boys' "performance" of gender roles (Butler 1988). According to Butler, gender is realized socially by a performative repetition of acts associated with being girls and boys, women and men-how we look, dress, move in the world, speak, think, feel, and behave. It is through such repetitive performance that gender is constituted and perpetuated.

For Butler and certain other feminist philosophers, the fact that our understanding of biological sex is deeply embedded in cultural assumptions and what we now call gender means that we should combine the concepts of sex and gender into a single construct: sex/gender. Gayle S. Rubin's influential 1975 essay, for example, "The Traffic in Women: Notes on the Political Economy of Sex," described what she called the sex/gender system: "the set of arrangements by which a society transforms biological sexuality into products of human activity, and in which these transformed sexual needs are satisfied." Rubin contends that, "Gender is a socially imposed division of the sexes" motivated primarily by economic considerations as 
women are commodified and exchanged within patriarchal societies $(1975,179)$. Historically, one man giving the gift of a daughter or a sister to another man for the purpose of matrimony fosters kinship ties between two men and the transfer of "sexual access, genealogical statuses, lineage names and ancestors, rights and people" to take place $(1975,177)$. Women become "gendered" when the distinction between male giver and female gift is made in such exchanges.

While some theorists have embraced the blended term "sex/gender" to stress how interdependent the two concepts are, others have adopted the practice of treating the term "gender" as superordinate to include beliefs, assumptions, and practices about biological sex. Raewyn Connell and Rebecca Pearse's definition of "gender" is an example: "Gender is the structure of social relations that centers on the reproductive arena, and the set of practices that bring reproductive distinctions between bodies into social processes" $(2015,11)$. In both cases-treating gender as the superordinate label, or adopting the blended term sex/gender-the point of this third strand is that the deep-rooted social and cultural assumptions about what it means to be a man or a woman, male or female make a clear distinction between "sex" and "gender" problematic.

The authority of science and scientific knowledge is often invoked to further various social, cultural, and political values. As a salient example, when infants were born with an apparent DSD (Difference in Sex Development), the result would be what Katrina Karkazis calls a "social emergency in which medical experts are called on to intervene." The breach of the social order "caused by the birth of a baby with atypical genitals (and thus no obvious gender assignment) produces a crisis that must be addressed because it threatens social norms" (2008, 96). The decision to pathologize what used to be called a hermaphroditic condition is a cultural one, not simply an objective diagnosis. A decision by doctors to do surgery to "fix" DSD infants' genitalia to make them into a boy or girl, was often based on their subjective assessment of genital size (Fausto-Sterling 2020b, 59-66). It has been only in the past few decades that a more patient-centered approach has emerged that questions whether infant surgery should be allowed until the person with DSD conditions can consent meaningfully (Davis 2015; Dreger 2015; Kessler 1998; Luthra 2020).

It should be remembered that homosexuality was pathologized in the American Psychiatric Association's Diagnostic and Statistical Manual of Mental Disorders (DSM) to varying degrees until $1987 .{ }^{15}$ The removal from the DSM was politically important to gay rights. Dr. Jack Drescher credits those changes for facilitating legal changes for homosexuals, and in particular the legal path toward same-sex marriage. Writing three years before the Supreme Court decision legalizing same-sex marriage, Drescher noted the progress of gay rights and declared: "Whatever that outcome, none of these changes in executing and discussion social policies that affect gay people would have occurred without the APA decision" $(2012,133)$.

The APA's decision was not necessarily the end of the story; it may have been a necessary condition for gay rights, but not a sufficient one. The role of science is unpredictable when it comes to issues of sexual and gender identity. There was 
a time when the search for the so-called "gay gene" was heralded by some gay rights advocates as proving that homosexuality was as an immutable characteristic and thus justified protection against discrimination. ${ }^{16}$ But as Robert Alan Brookey warned, had a gay gene been discovered, it could have become the basis for new lines of pathologizing tests and treatments by the biomedical industry $(2002,128) .{ }^{17}$

The fact that research is emerging in the 21 st century that claims there may be a genetic explanation for gender identity is a mixed blessing, and should be treated with caution. The most provocative research in this vein posits that transgender people appear to be born with brains more similar to the gender with which they identify rather than their assigned gender (Wu 2016). ${ }^{18}$ On one hand, such research may persuade those who doubt the "realness" of expressions of gender dysphoria. On the other hand, as soon as one identifies a genetic basis for behavior some consider abnormal, it is not difficult to envision the emergence of tests and interventions with less than supportive aims (Swartz 2018). This does not mean such research should not be conducted, it means that the results need to be interpreted with care (see Powell, Shapiro, \& Stein 2016).

In short, this last strand of thinking about sex/gender reminds us of the influence of culture and politics. As Fausto-Sterling noted in an essay titled "Science Won't Settle Trans Rights" — citing political scientist Laura Ephraim's important work (2017) on the political work that scientific "world-building" performs:

Gone are the days when only medical experts define sex, gender, and sexuality. As social movements disrupt a previously comfortable scientific consensus, traditional scientific groups grapple with questions of authority. Who, in this new world, speaks for science, and for whom does science speak? The answer is both unsettling and unsettled.

Similarly, Eric Vilain suggests the scientific situation with biological sex is sufficiently unclear that it might be easier just to ask people their gender identity:

So if the law requires that a person is male or female, should that sex be assigned by anatomy, hormones, cells or chromosomes, and what should be done if they clash? "My feeling is that since there is not one biological parameter that takes over every other parameter, at the end of the day, gender identity seems to be the most reasonable parameter," says Vilain.

(Ainsworth 2018) $^{19}$

\section{Defining gender in the 21st century: Fluid and multi-dimensional}

Not surprisingly, different definitions of "gender" have proliferated, ranging from very broad descriptions to sophisticated efforts to specify how gender is understood in a specific population. 
An example of a broad definition is the one cited previously from the World Health Organization: "Gender refers to the roles, behaviours, activities, attributes and opportunities that any society considers appropriate for boys and girls, and men and women" (Manandhar et al. 2018). Or, consider the American Psychological Association:

Gender refers to the attitudes, feelings, and behaviors that a given culture associates with a person's biological sex. Behavior that is compatible with cultural expectations is referred to as gender-normative; behaviors that are viewed as incompatible with these expectations constitute gender non-conformity.

$(2012,11)$

Such definitions are necessarily general, since specific gender norms can vary over time and across cultures. As sociologist Mary Holmes has stated, gender is a complex phenomenon, the meaning of which in a specific moment in history and in a specific geographic location is influenced by issues of class, race, beliefs about the human body, and political ideology (2007). Accordingly, the best an initial definition of gender can do is to gesture toward the fact that cultures have different norms and expectations for women and men, though the details vary considerably.

Furthermore, many gender theorists see the constraining influence of gender norms as a social force to be opposed. Some favor the idea and practice of gender bending - that is, dressing or behaving in a non-gender conforming manner-as a form of activism to challenge dominant gender norms. Some promote the labels "gender fluid" or "gender fluidity" to stress the wide variety of social, cultural, and individual preferences (Hines 2018). Of course, what counts as gender bending is just as culturally variable as gender itself. A man wearing high heels and a lengthy wig might be considered gender bending today, but both were quite conventional for privileged men in Europe in the 17th and 18th century.

In contrast to efforts by some gender theorists to define gender broadly and deliberately loosely, other scholars have attempted to become increasingly detailed and specific in their understanding of how gender is understood in specific cultures. Psychologists in the United States studying gender are a good example.

The Bem Sex Role Inventory was an attempt to measure masculinity and femininity as discrete if potentially complementary wholes, that is, the different items on the masculine and feminine list would be added together to create a single score on masculinity and a single score on femininity. This means that the BSRI treats masculinity and femininity as distinct dimensions of one's personality, even if one person could score high in both. In the parlance of social science, the concepts of masculinity and femininity are each treated as unidimensional.

In recent decades, social scientists have explored masculinity and femininity as multi-dimensional, suggesting that a single individual might conform to some societal expectations regarding their gender but not others.

An example of a multi-dimensional approach to gender can be found in the work of psychologist James R. Mahalik and his colleagues, who produced the 
"Conformity to Masculine Norms Inventory" (2003) and the "Conformity to Feminine Norms Inventory" (2005). These norms include the following:

\title{
Conformity to Masculine Norms Inventory
}

$\begin{array}{lll}\text { Winning } & \text { Controls Emotions } & \text { Risk Taker } \\ \text { Accepts Violence } & \text { Playboy } & \text { Dominance } \\ \text { Power over Women } & \text { Self-Reliant } & \text { Work is Primary } \\ \text { Disdain for Homosexuality } & \text { Pursues Status } & \end{array}$

\section{Conformity to Feminine Norms Inventory}

\author{
Nice in Relationships \\ Cares for Children \\ Values Sexual Fidelity
}

Values Thinness

Domestic

Modest

Interested in Appearance

Values Romance

Mahalik et al.'s inventories have been cited by literally hundreds of other studies and are influential examples of an effort to operationalize what is meant by gender in the 21st century, though-like many of the terms in the Bem Sex Role Inventorymost of the norms might be understood as stereotypes of how masculinity and femininity are perceived. Other examples of scales or inventories that explore femininity multi-dimensionally include the Adolescent Femininity Ideology Scale (Tolman \& Porche 2000) and the Feminine Gender Role Stress Scale (Gillespie \& Eisler 1992). Other examples that explore masculinity multi-dimensionally include the Male Role Norms Scale (Thompson \& Pleck 1986) and the Male Role Norms Inventory (Levant et al. 1992). By 1990, hundreds of tests and measures associated with gender roles and issues had been developed and made available in handbooks (Beere 1990a, 1990b).

While social scientists have tried to articulate conceptions of gender with increasing specificity and accuracy, other scholars have advocated an understanding of gender that goes beyond the traditional categories of masculine and feminine with such concepts as gender fluidity, variability, transgender, gender-queer, and gender nonconformity. In The Apartheid of Sex: A Manifesto on the Freedom of Gender, Martine Rothblatt advocates a chromatic system of gender would differentiate among hundreds of different gendered personality types-343 "shades" of gender, in fact (1995).

Thus, for various reasons, we enter the 21st century with less certainty and consensus about how to define "sex" and "gender" than in any other point in modern history. The situation has become even more uncertain in light of the Transgender Exigency, and so it is to that topic I now turn. 


\section{Notes}

1 McCloskey (2019, 50-51, emphasis in the original).

2 Email to the author, July 31, 2021.

3 I limit my focus mostly to the United States and approximately the past seven decades for the purposes of clarity. If one looks beyond mainstream and mostly white U.S. culture, the notion of third sex (or more) has an older history, including among Native Americans. And in the United States one can find antecedents of transgender lifestyles dating back centuries. See, for example, Susan Stryker's Transgender History (2017) and Jen Manion's fascinating book, Female Husbands: A Trans History (2020).

4 See, for example, Crisler and McHugh (2011).

5 "Hermaphrodite" is no longer the term preferred to describe DSD individuals, as I discuss later on. See Vilain et al. (2007) and Lundberg, Hegarty, and Roen (2018).

6 For a detailed account of Money's work and its legacy, see Germon (2009), especially Chapter 2.

7 The phrase "gender role" can be found as early as 1955 (in Money, Hampson, \& Hampson 1955), but Stoller's formulation is generally credited as the one informing subsequent gender theorists: "The term [gender identity] was introduced to the psychiatric/ psychoanalytic worlds in 1964" in Stoller's article (Green 2010, 1457).

8 Such tests included the Wechsler Adult Intelligence Scale (WAIS) Masculinity-Femininity Index, the masculinity and femininity scales of the California Psychological Inventory, the Masculinity-Femininity score of the Franck Drawing Completion Test, and the Mf scale of the Minnesota Multiphasic Personality Inventory (MMPI). These tests were used as diagnostic tools for mental health purposes, or, in the case of the Franck Drawing Completion Test, an effort to explore the relationship between personality attributes and creativity.

9 I suspect Bem would have been a fan of the subreddit group, "pointlessly gendered": www.reddit.com/r/pointlesslygendered/

10 See the Corpus of Historical American English (COHA) and Google Books Ngram Viewer (https://books.google.com/ngrams/) search for "gender" in English and American English.

11 Other examples include the Hijra of South Asia, dating back centuries (Nanda 1994), the so-called third gender muxe of the indigenous Zapotec people of Mexico (Stephen 2002); the femmenielli of Neapolitan culture that dates back centuries (Bertuzzi 2015), and the kathoey (กะเทย) of Thailand (Morris 1994; Totman 2003).

12 See Richardson (2013) for a valuable account of the various efforts in the past century to find "sex itself" in the human genome.

13 Fausto-Sterling's oft-cited figure of $1.7 \%$ is based on a research review conducted with her students and reported in the American Journal of Human Biology (Blackless et al. 2000). Hull (2003) accuses Blackless et al. of a variety of serious errors and suggests a figure of $0.37 \%$. Sax's (2002) figure of $0.018 \%$ is based on a definition that only "counts" congenital adrenal hyperplasia $(\mathrm{CAH})$ and complete androgen insensitivity syndrome as DSD conditions. Conditions that Sax excludes but Fausto-Sterling includes are LateOnset Congenital Adrenal Hyperplasia, Vaginal Agenesis, and any sex chromosome combinations other than XX or XY (including but not limited to Klinefelter syndrome 47, XXY, Turner syndrome 45X, XXX, XYY, and other "less frequent arrangements"). Sax's explanation for the exclusion of these categories is that they do not cause ambiguous genitalia or, he believes, "any confusion regarding sexual identity" $(2002,177)$. He notes that $88 \%$ of those whom Fausto-Sterling classifies as "intersex" (DSD) are those with Late-Onset Congenital Adrenal Hyperplasia or nonclassic CAH (LOCAH). Hull makes a similar argument $(2003,113)$. Sax claims: "From a clinician's perspective, however, LOCAH is not an intersex condition. The genitalia of these babies are normal at birth, and consonant with their chromosomes: XY males have normal male genitalia, and XX females have normal female genitalia" (176). Any medical problems people with 
LOCAH have, Sax argues, are not "intersexual in nature" (176). See also Fausto-Sterling (2020b, 324-326).

14 The idea that the meaning of individual scientific terms, including so-called "observation terms," depend on a larger theory is typically credited to Duhem (1954) and Hanson (1958).

15 After lobbying by gay rights advocates, "in December 1973, APA's Board of Trustees voted to remove homosexuality from the DSM" (Drescher 2015, 571). The removal was neither immediate, nor complete. If a person with same-sex attraction was distressed, they could still be diagnosed as having "Sexual Orientation Disturbance" (SOD), according to the DSM II. In DSM III, published in 1980, "Sexual Orientation Disturbance" was re-named "Ego Dystonic Homosexuality." Thus even in 1980, "cures" and "conversion therapies" persisted and doctors could justify their actions with reference to the DSM as a source of scientific authority. Thus, while the change in 1973 was significant and is still widely celebrated as a turning point, it did not end efforts by many to treat homosexuality as a pathology (Drescher 2015, 571). It was only in 1987 that a revision of the DSM III finally and permanently removed "Ego Dystonic Homosexuality."

16 For a critique of such scientific research, see Stein (1999). For an argument against an entrenched "bioessentialist" approach to conceptualizing LGBTQ citizenship, see Wuest (2022).

17 The current scientific consensus appears to be that there is no such thing as the gay gene (Lambert 2019).

18 The idea that there are meaningfully different "male" and "female" brains has been critiqued at length (Eliot 2009; Rippon 2019). There are observable differences between certain physical features of female and male brains (cortical thickness, white matter variation, etc.), and it is these differences that have been compared to transgender subjects. Some studies conclude that the brains of transgender individuals are closer in structure, function, and activation patterns to the brains of their self-identified gender. See, for example, Bakker (2018) and Guillamon, Junque, and Gómez-Gil (2016).

19 As a scholar of argumentation, I need to note here that the existence of difficult border cases or exceptions does not completely vitiate the utility of categories. The headline to Ainsworth's article is: "Sex Redefined: The Idea of 2 Sexes is Overly Simplistic," followed with the subtitle "Biologists now think there is a larger spectrum than just binary female and male" (2018). While facially valid in light of research on people with DSD, there are some who infer from such headlines that the ideas of male and female are mere fictions. An equally valid headline could read: "The Idea of 2 Biological Sexes is Accurate for $98 \%+$ of the population." That is, because the vast majority of humans have an anatomy, hormones, cells, and chromosomes that are consistently male or female, most of the time and in most contexts, people use the words "female" and "male" without confusion or fear of contradiction. Once we add the idea of gender identity, of course, matters become more complicated. 